\begin{tabular}{|c|}
\hline $\begin{array}{l}\text { DIGITALNI SERVO SISTEM ZA } \\
\text { UPRAVLJANJE INFRACRVENIM } \\
\text { LOKATOROM }\end{array}$ \\
\hline $\begin{array}{l}\text { Aleksandar Viličić, dipl. inž. } \\
\text { potpukovnik mr Mirko Jezdimirović, dipl. inž., } \\
\text { Vojnotehnički institut }\end{array}$ \\
\hline
\end{tabular}

Rezime:

$U$ radu je predstavljen digitalni servo sistem sa pogonskim elektromotorom koji zamenjuje postojeći elektrohidraulički servo pogon na uređaju za upravljanje IC lokatorom, koji obezbeđuje zahtevanu tačnost pozicioniranja i praćenja sa minimalnim brzinama.

Ključne reči: digitalni servo sistem, digitalni regulator, upravljanje, infracrveni lokator, automatsko upravljanje.

\title{
DIGITAL SERVO SYSTEM FOR THE INFRARED (IR) DETECTION DEVICE
}

\section{Summary:}

This paper describes a digital servo-system with a driving electromotor which substitutes the existing electrohydraulical servo-system on an IR localizer control device. Thus realized, a digital electrical servo-system provides requested accuracy of positioning and tracking with minimal velocities.

Key words: digital servo-system, digital regulator, control, IR localizer, automatic control.

\section{Uvod}

Raznovrsna primena servo sistema u sistemima naoružanja i vojne opreme uslovljena je njihovom namenom. Zavisno od namene sistema naoružanja definišu se i različiti zahtevi u pogledu servo sistema. Jedna od karakterističnih primena servosistema u sistemima naoružanja i vojne opreme jeste da servo sistem tačno zauzme željeni položaj i dovoljno dugo i stabilno drži taj položaj ili vrši praćenje sa minimalnom brzinom, što je karakteristično za servo sisteme kod: nišanskih uređaja, protivoklopnih vođenih raketa, laserskih obeleživača cilja i sl. 
radu je prikazan primer primene servo sistema kod uređaja za upravljanje infracrvenog detektora rakete (IC lokator). Dosadašnji elektrohidraulični servo sistem zamenjen je električnim servo sistemom sa digitalnim regulatorom koji pokreće jednosmerni elektromotor. $U$ radu je opisan električni servo sistem sa digitalnim regulatorom za upravljanje uređajem za infracrvenu detekciju rakete (IC lokator). Prikazan je matematički model digitalnog servo sistema. Na funkcionalnom modelu izvršeno je snimanje karakteristika servo sistema, obrađeni su dobijeni rezultati i upoređeni sa rezultatima dobijenim na osnovu ispitivanja dosadašnjeg elektrohidrauličkog servo sistema.

\section{Pregled oznaka}

Vt Napon na motoru

$T_{\text {em }} \quad$ Momenat motora

$R_{a} \quad$ Otpornost namotaja rotora

$i_{\text {mot }} \quad$ Prenosni odnos planetarnog prenosa

$i_{\text {red }} \quad$ Prenosni odnos reduktora

$i_{p o} \quad$ Prenosni odnos reduktora potenciometra

$K_{p} \quad$ Proporcionalni koeficijent pojačanja

$K_{i} \quad$ Integralni koeficijent pojačanja

$e_{a} \quad$ Indukovana elektromotorna sila

$i_{a} \quad$ Struja rotora

$T \quad$ Vreme odabiranja (sample time)

$L \quad$ Induktivnost namotaja motora

$K_{E} \quad$ Električna konstanta motora

$\omega_{m} \quad$ Ugaona brzina motora

$T_{\text {em }} \quad$ Elektromehanička konstanta motora

$B_{\text {em }} \quad$ Momenat viskoznog trenja u ležajevima motora

$J_{e m} \quad$ Momenat inercije rotora motora

$J \quad$ Ukupni momenat inercije sveden na rotor motora

$B \quad$ Ukupni momenat viskoznog trenja sveden na rotor motora

$K_{T} \quad$ Mehanička konstanta motora

$I_{m} \quad$ Mehanička vremenska konstanta

$I_{m 1} \quad$ Električna vremenska konstanta motora

$s \quad$ Operator laplasove transformacije

$z \quad$ Operator $z$-transformacije

$K_{h} \quad$ Skal faktor D/A konverzije

$K_{h} \quad$ Skal faktor inkrementalnog enkodera 


\section{Opis sistema}

Servo sistem za pokretanje IC lokatora treba da zadovolji opšte taktičko-tehničke zahteve za vođenje i upravljanje protivoklopnih vođenih raketa, da obezbedi zahvat cilja i nišanjenje na izabranu tačku na cilju. $\mathrm{Na}$ osnovu podataka sa IC davača formira se razlika položaja rakete (njenog trasera) i ose nišanjenja. Na osnovu toga vrši se popravka putanje rakete i, shodno algoritmu praćenja, ostvaruje navođenje rakete na cilj.

Pokretanje i upravljanje IC lokatora po pravcu vrši se preko servo sistema pravca koji najčešće služi za pokretanje i upravljanje obrtne platforme po pravcu na kojoj se nalaze i ostali uređaji pored IC lokatora, dok se za pokretanje i upravljanje po visini koristi servo sistem samo za pokretanje IC lokatora po visini. Servo sistem treba da omogući operateru mogućnost nišanjenja na stacionarni ili pokretni cilj. Komande za zauzimanje pozicije i praćenje cilja zadaju se putem upravljačke palice. Funkcionalna šema sistema sa IC vođenim raketnim sistemom za protivoklopnu borbu prikazana je na slici 1.

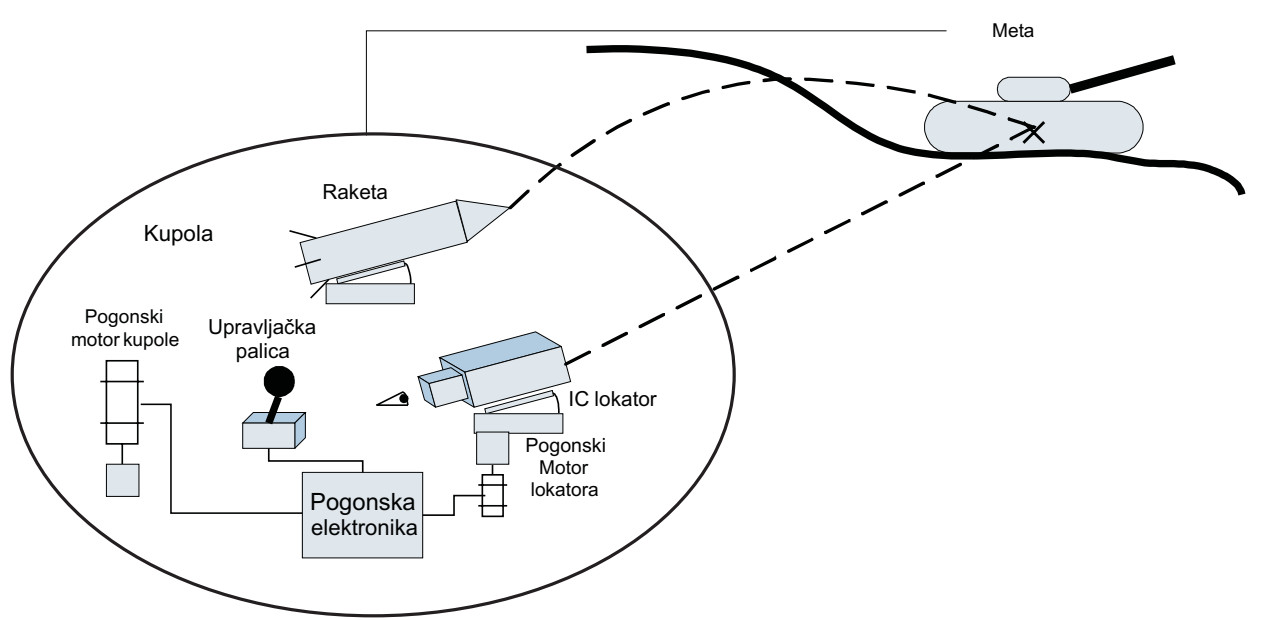

Slika 1 - Funkcionalna šema sistema za protivoklopnu borbu sa protivoklopnim raketama sa IC navođenjem

Prethodno realizovan servo sistem za pokretanje IC lokatora po visini bio je sa elektrohidrauličkim pogonom, gde upravljački signal zakreće elektrohidraulički servo razvodnik. Radi modernizacije ovog sistema postavljeni su novi projektni zahtevi da se pokretanje IC lokatora ostvari pomoću elektromotora, a da karakteristike servo sistema ostanu iste ili budu nešto bolje. 
Iz namene servo sistema proističu zahtevi za servo sistem:

- nema "drifta“ izlazne osovine pri nultom komandnom signalu brzine,

- minimalna ugaona brzina $0,3 \mathrm{mrad} / \mathrm{s}$,

- maksimalna ugaona brzina $80 \mathrm{mrad} / \mathrm{s}$,

- polje pokretanja po elevaciji $-10^{\circ}$ do $+15^{\circ}$.

\section{Matematički model servo sistema za upravljanje IC lokatorom cilja}

Za pokretanje IC lokatora po elevaciji koristi se jednosmerni (DC) motor upravljan strujom rotora. DC motor sa permanentnim magnetom, upravljan strujom rotora, na koji je preko reduktora vezano inercijalno opterećenje, može se predstaviti sledećim matematičkim jednačinama [1]:

$$
\begin{aligned}
& V_{t}(t)=e_{a}(t)+R_{a} i_{a}(t)+\frac{L d i_{a}(t)}{d t} \\
& e_{a}(t)=K_{E} \omega_{m}(t) \\
& T_{e m}(t)=\left(B_{e m}+B_{W L}\right) \omega_{m}(t)+\left(J_{e m}+J_{W L}\right) \frac{d \omega_{m}(t)}{d t}=B \omega_{m}(t)+J \frac{d \omega_{m}(t)}{d t} \\
& T_{e m}(t)=K_{T} i_{a}(t) .
\end{aligned}
$$

Koristeći Laplasovu transformaciju, sa pretpostavkom da je električna vremenska konstanta znatno manja od mehaničke vremenske konstante, prenosne funkcije DC motora mogu se izraziti u sledećem obliku:

$$
\begin{aligned}
& \omega_{m}(s)=\frac{K_{T}}{B} \frac{1}{1+\tau_{m} s} I_{a}(s), \\
& I_{a}(s)=K_{2} \frac{1+\tau_{m} s}{1+\tau_{m 1} s} V_{t}(s),
\end{aligned}
$$

gde je:

$$
\begin{aligned}
& K_{2}=\frac{B}{K_{E} K_{T}+R_{a} B}, \\
& \tau_{m}=\frac{J}{B}, \\
& \tau_{m 1}=\frac{R_{a} B}{K_{E} K_{T}+R_{a} B} \tau_{m}
\end{aligned}
$$


Za linearizovani matematički model potrebno je podesiti parametre regulatora tako da odziv sistema zadovolji zahteve (1) u svim uslovima rada sistema.

Linearizovane prenosne funkcije objekta upravljanja korišćene pri simulaciji imaju oblik:

$$
\begin{aligned}
& \frac{I_{m}}{V_{t}(s)}=\frac{K_{2}\left(1+\tau_{m} s\right)}{\left(1+\tau_{m 1} s\right)}=G_{1}(s) \\
& \frac{\omega_{m}(s)}{I_{m}(s)}=\frac{K}{\left(1+\tau_{m} s\right)}=G_{2}(s) .
\end{aligned}
$$

\section{Praktična realizacija digitalnog regulatora pogona IC lokatora}

Pogonski motor preko reduktora i ozubljenog sektora pokreće IC lokator po visini. Prenosni odnos (redukcija) reduktora i ozubljenog sektora je $i_{\text {red }}=127$. Na osovinu motora povezan je planetarni reduktor prenosnog odnosa $i_{\text {mot }}=128$. Ugrađen je DC motor Maxon A-max 32 snage $15 \mathrm{~W}$ sledećih karakteristika:

- nominalni napon $24 \mathrm{~V}$,

- nominalna snaga $15 \mathrm{~W}$,

- nominalna brzina $5860 \mathrm{o} / \mathrm{min}$,

- nominalni momenat $129 \mathrm{mNm}$,

- konstanta momenta $38,2 \mathrm{mNm} / \mathrm{A}$,

- konstanta brzine $25 \mathrm{o} / \mathrm{min} / \mathrm{V}$,

- mehanička vremenska konstanta $20 \mathrm{~ms}$ i

- otpornost namotaja $7,13 \Omega$.

$\mathrm{Na}$ osovinu motora ugrađen je optički inkrementalni enkoder HEDS 5540 sa tri izvoda i 500 zareza po krugu. Elektronskim brojačem se broj podela po obrtu rotora elektromotora pretvara u 2000.

$\mathrm{Na}$ osovinu IC lokatora preko ozubljenog sektora prenosnog odnosa $i_{\text {pot }}=468 / 36=13$ povezan je žičani potenciometar OHMAG sa 1000 namotaja, koji se koristi za određivanje ugaone pozicije IC lokatora. Ovaj potenciometar i njegov reduktor nije menjan u odnosu na originalni sistem.

Razlika u očitavanju položaja između dva navoja potenciometra je $\Delta \alpha_{p o t}=\frac{2 \pi}{1000 * i_{p o t}}=0,483 \mathrm{mrad}$. 
Potenciometar se ne nalazi u petlji upravljanja već služi za kopiranje dostignutog ugla IC lokatora na lanser protivtenkovske (PT) rakete i može se koristiti i kao nezavisni davač ugla. Faktor razmere za računanje ugla IC lokatora je $k_{\alpha}=15,97 \mathrm{mrad} / \mathrm{V}$.

Upravljanje servo sistemom je digitalno. Zahtevana ugaona brzina se zadaje na osnovu otklona upravljačke palice putem potenciometra.

Mikrokontroler kao signal upravljanja daje impulsno širinsko modulisani signal (PWM signal) koji preko tranzistorskih drajvera (pretpojačivača) i snažnog tranzistorskog $\mathrm{H}$-mosta sa MOSFET tranzistorima upravlja DC motorom. Motor preko višestepenog reduktora pokreće IC lokator po visini. $\mathrm{Na}$ navedeni način ostvarena je kvadratna modulacija, tako da je frekvencija impulsa na motoru duplo veća od frekvencije rada prekidačkih tranzistora, odnosno komande. $\mathrm{Na}$ izlazu $\mathrm{H}$-mosta vezan je motor. $\mathrm{Na}$ osovinu motora ugrađen je inkrementalni enkoder koji služi za merenje ugaone brzine motora čiji se signali vode na kolo za detekciju impulsa i smera obrtanja. Merenje struje obavlja se pomoću galvanski razdvojenog davača koji radi na principu Holovog efekta čiji se izlaz vodi na prvi kanal A/D konvertora.

Regulacija unutrašnje petlje obavlja se kaskadnim PID regulatorom koji je realizovan programski.

Regulacija spoljašnje petlje vrši se kaskadnim PID regulatorom sa izmeštenim proporcionalnim dejstvom koji je realizovan programski. Blok-šema upravljanja servo sistemom prikazana je na slici 2.

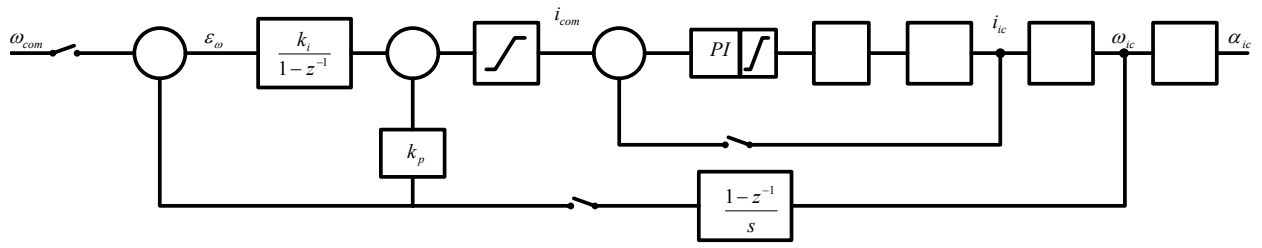

Slika 2 - Blok-šema električnog servo sistema sa digitalnim regulatorom za upravljanje IC lokatorom po visini

Perioda PWM signala, s obzirom na karakteristike pogonskog motora i mikrokontrolera, iznosi $66 \mathrm{~ns}$, a perioda odabiranja strujne petlje je $8 \mathrm{~ms}$.

Diskretna prenosna funkcija ovako realizovanog pogona (čiji je blok dijagram prikazan na slici 2), uzimajući u obzir da je perioda PWM signala više od 100 puta brža od periode odabiranja brzinske petlje i da se električna vremenska konstanta može zanemariti i u odnosu na mehaničku vremensku konstantu, ima karakterističnu jednačinu [2]:

$$
z^{3}+a_{2} z^{2}+a_{1} z+a_{0}=0
$$

gde su:

$$
\begin{aligned}
& \mathrm{a}_{2}=-(1+\mathrm{A})+\mathrm{K}\left(\mathrm{T}-\mathrm{T}_{\mathrm{m}}+\mathrm{AT}_{\mathrm{m}}\right)\left(\mathrm{K}_{\mathrm{p}}+\mathrm{K}_{\mathrm{i}}\right) \\
& \mathrm{a}_{1}=\mathrm{A}-\mathrm{KTA}\left(\mathrm{K}_{\mathrm{p}}+\mathrm{K}_{\mathrm{i}}\right)-\mathrm{KTK}_{\mathrm{p}}+\mathrm{KT}_{\mathrm{m}}(1-\mathrm{A})\left(2 \mathrm{~K}_{\mathrm{p}}+\mathrm{K}_{\mathrm{i}}\right) \\
& \mathrm{a}_{0}=\mathrm{KTAK}_{\mathrm{p}}-\mathrm{KT}_{\mathrm{m}} \mathrm{K}_{\mathrm{p}}(1-\mathrm{A}),
\end{aligned}
$$


gde su:

$\mathrm{K}=\mathrm{K}_{\mathrm{h}} \mathrm{K}_{\mathrm{A}} \mathrm{K}_{n} \mathrm{~K}_{\mathrm{m}}$ i $\mathrm{A}=\mathrm{e}^{-\mathrm{T} / \mathrm{rm}}$.

Navedeni koeficijenti zavise od parametara sistema i pojačanja regulatora, pa je moguće podesiti parametre regulatora da bi se dobile zahtevane dinamičke i statičke karakteristike sistema.

\section{Rezultati merenja karakteristika realizovanog servo sistema sa digitalnim regulatorom za upravljanje IC lokatorom cilja}

Na funkcionalnom modelu IC lokatora izvršena je ugradnja servo sistema, kao i merenja parametara servo sistema za upravljanje po elevaciji. Za akviziciju i obradu podataka korišćen je programski paket LabVIEW. Merenja su vršena na bazi iskustava na realizaciji drugih servo sistema sa digitalnim regulatorom [3]. Merena je vrednost naponskog signala na potenciometru pozicije, a brzina se dobija diferenciranjem pozicije. Treba napomenuti da je na elektrohidrauličnom sistemu za pokretanje IC lokatora brzina lokatora po elevaciji računata na isti način (analognim diferencijatorom) i korišćena u povratnoj sprezi kao signal brzine. Zahvaljujući upotrebi istih davača za merenje signala oba pogona moguće je direktno poređenje izmerenih podataka na oba sistema. Zbog diskretnog broja namotaja žičanog potenciometra javljaju se skokovi naponske veličine izmerenog ugla, pa je vršena filtracija ovog signala niskopropusnim filterom 3. reda propusne učestanosti $8 \mathrm{~Hz}$. Izmerena je minimalna brzina pokretanja od $0,0615 \mathrm{mrad} / \mathrm{s}$. Rezultati merenja minimalne brzine IC lokatora sa električnim servo sistemom prikazani su na slici 3.

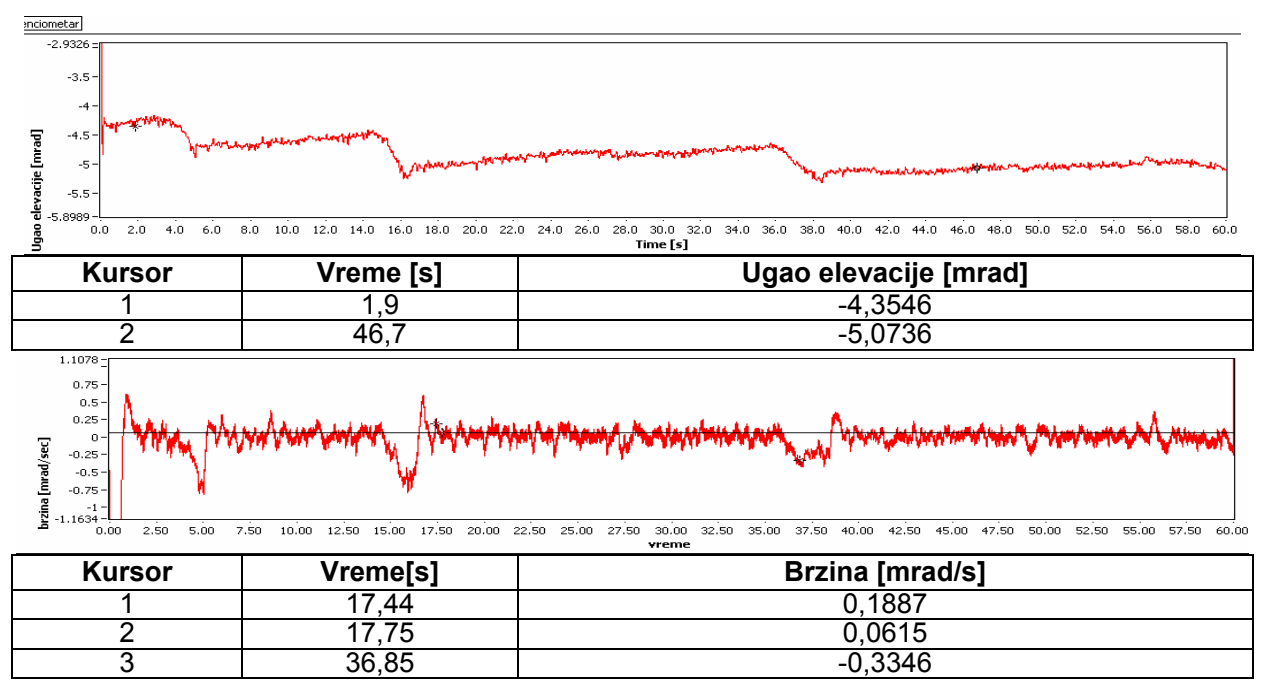

Slika 3 - Dijagram minimalne brzine servo sistema za pokretanje IC lokatora po visini 
Izmerena je maksimalna brzina od $89,77 \mathrm{mrad} / \mathrm{s}$, odnosno $-79,72$ $\mathrm{mrad} / \mathrm{s}$ za pokretanje IC lokatora nagore i nadole, respektivno. Dijagram maksimalne brzine prikazan je na sl. 4.

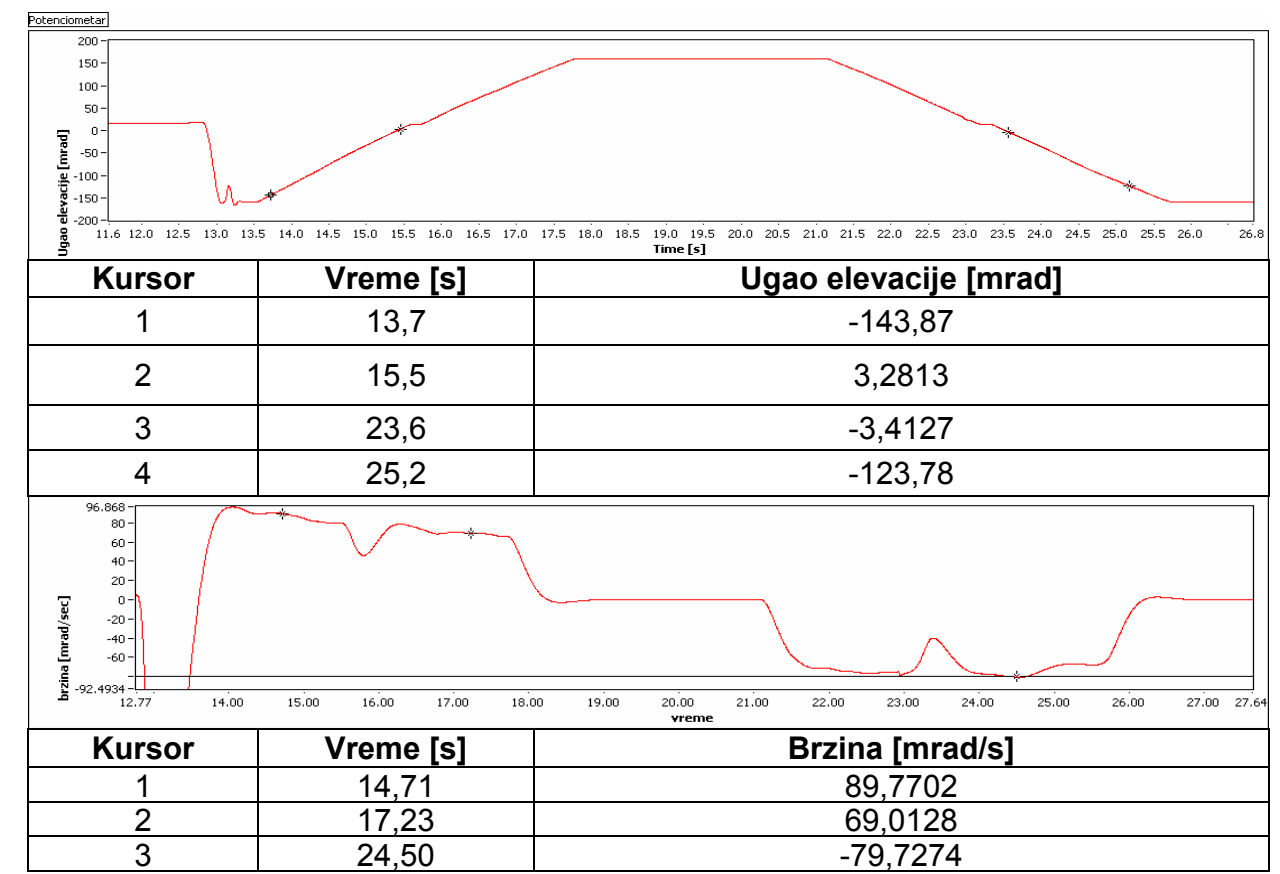

Slika 4 - Dijagram maksimalne brzine servo sistema za pokretanje IC lokatora po visini

Maksimalno ubrzanje servo sistema određuje se iz dijagrama na sl. 5 i iznosi:

$\ddot{\alpha}=\frac{\Delta \omega}{\Delta t}=\frac{49,88+51,99}{13,7-13,52}=565,7 \mathrm{mrad} / \mathrm{s}^{2}$

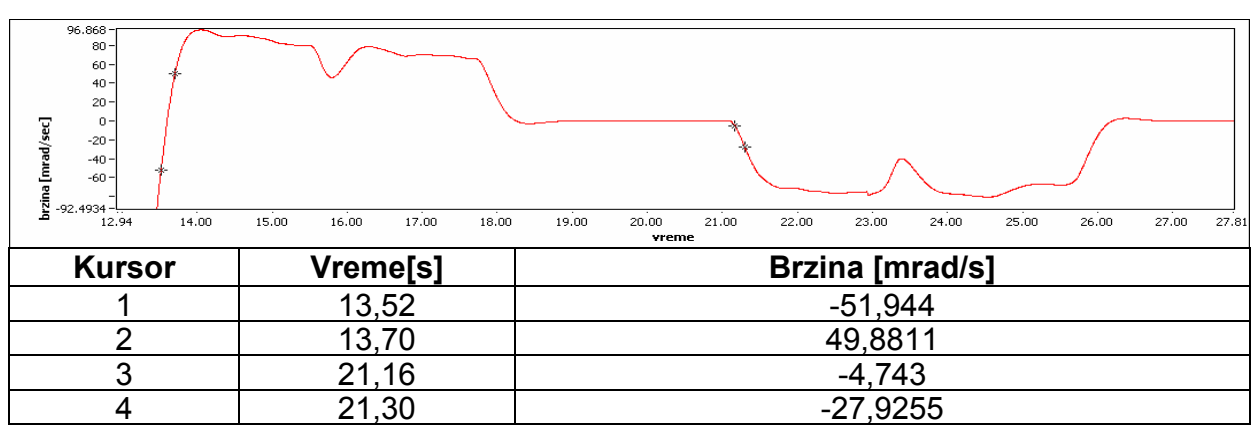

Slika 5 - Dijagram maksimalnog ubrzanja servo sistema za pokretanje IC lokatora po visini 
Iz zahteva za pogon IC lokatora po visini potrebno je da pri nultoj komandi brzine objekat upravljanja drži poziciju bar $30 \mathrm{~s}$. Rezultati ovih merenja prikazani su na slici 6 .

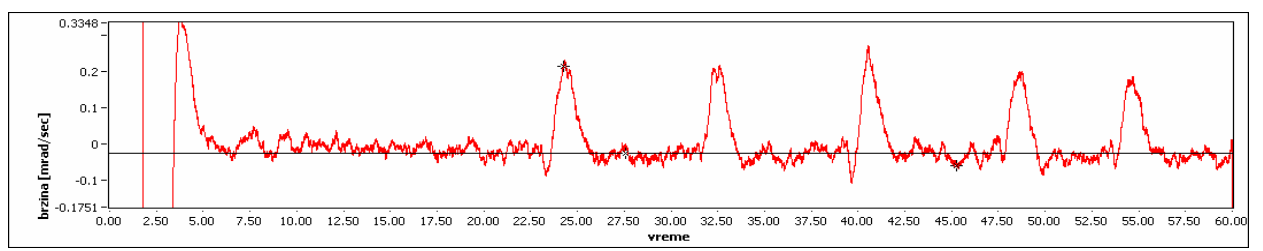

\begin{tabular}{|c|c|c|}
\hline Kursor & Vreme [s] & Brzina [mrad/s] \\
\hline 1 & 24,26 & 0,2134 \\
\hline 2 & 27,58 & $-0,0261$ \\
\hline 3 & 45,26 & $-0,0594$ \\
\hline
\end{tabular}

Slika 6 - Dijagram držanja zadatog (željenog) položaja servo sistema za IC lokator po visini

Na sistemu za pokretanje IC lokatora sa elektrohidrauličkim pogonom rezultati merenja minimalne brzine su snimljeni i prikazani na slici 7 . Minimalna brzina pokretanja IC lokatora, nadole $(\varepsilon), \dot{\varepsilon}=\frac{\Delta U[\mathrm{mrad}]}{\Delta T[\mathrm{~s}]}$, $\dot{\varepsilon}_{1}=\frac{23,41-24,76}{8-1,2}=-\frac{1,35}{6,8}=-0,1985[\mathrm{mrad} / \mathrm{s}]$, $\dot{\varepsilon}_{2}=\frac{22,44-23,41}{26-14}=-\frac{0,97}{12}=-0,08[\mathrm{mrad} / \mathrm{s}]$.

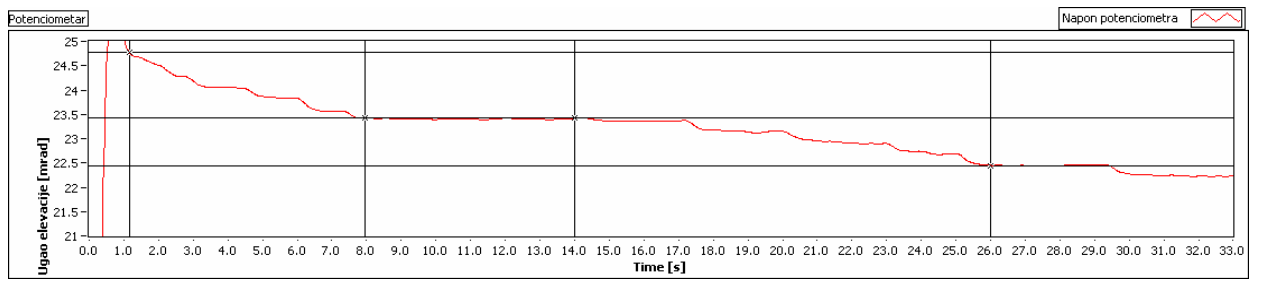

\begin{tabular}{|c|c|c|}
\hline Kursor & Vreme [s] & Ugao elevacije [mrad] \\
\hline 1 & 1,2 & 24,7654 \\
\hline 2 & 8,0 & 23,4185 \\
\hline 3 & 14,0 & 23,4163 \\
\hline 4 & 26,0 & 22,4492 \\
\hline
\end{tabular}

Slika 7 - Dijagram minimalne brzine elektrohidrauličkog servo sistema za pogon IC lokatora po visini 
Maksimalna brzina i ubrzanje izmereni su na elektrohidrauličkom pogonu IC lokatora po elevaciji, a rezultati su prikazani na slici 8.

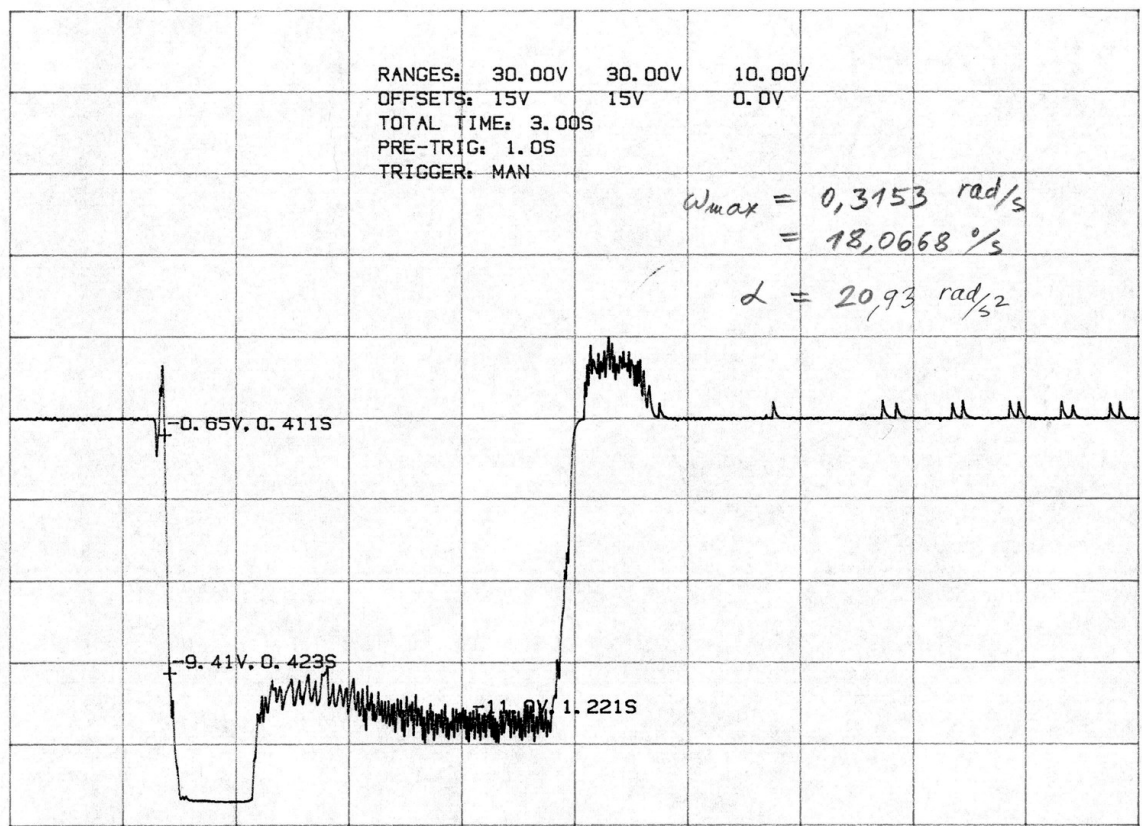

Slika 8 - Dijagram maksimalne brzine i ubrzanja elektrohidrauličkog servo sistema za pogon IC lokatora po visini

Rezultati merenja držanja zadate pozicije za elektrohidraulički pogon IC lokatora po elevaciji prikazani su na slici 9.

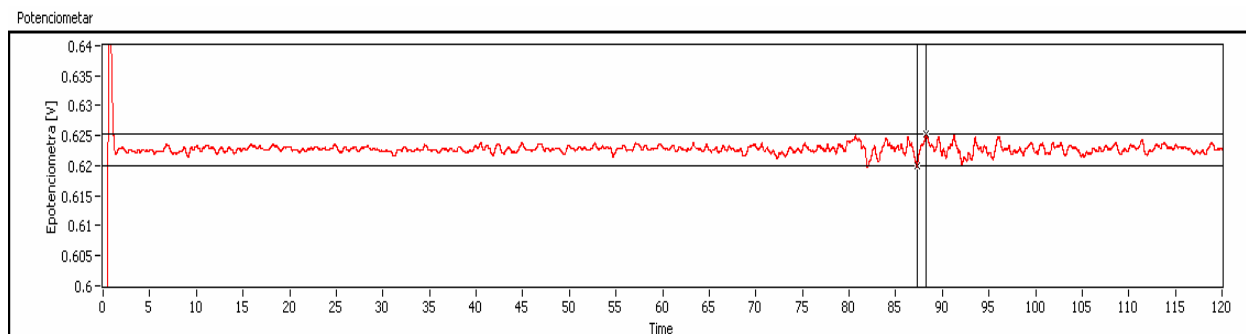

\begin{tabular}{|c|c|c|}
\hline Kursor & Vreme [s] & E potenciometra [V] \\
\hline 1 & 87,3146 & 0,620005 \\
\hline 2 & 88,2612 & 0,625233 \\
\hline
\end{tabular}

Ugao IC lokatora je između 38,82 i 39,15 mrad.

Slika 9 - Dijagram držanja zadatog (željenog) položaja elektrohidrauličkog servo sistema za pogon IC lokatora po visini 
U radu je prikazan realizovan električni servo sistem sa digitalnim regulatorom, primenjen na podsistemu za upravljanje IC lokatora cilja za vođenje jedne protivoklopne rakete. Karakteristika ovog servo sistema je da tačno i u dovoljno dugom periodu (za sve vreme leta IC navođene protivoklopne rakete) stabilno zadržava željeni položaj ili prati cilj sa minimalnom brzinom kretanja. Na ovaj način se, na osnovu podataka sa IC davača, formira signal razlike položaja rakete (njenog trasera) i ose nišanjenja shodno algoritmu vođenja i ostvaruje navođenje rakete na označeni i izabrani cilj.

U radu su korišćene klasične metode matematičkog modeliranja servo sistema, dok je akvizicija i obrada podataka merenja pojedinih karakteristika servo sistema obavljena upotrebom programskog paketa LabVIEW. Dobijeni rezultati merenja karakteristika servo sistema na funkcionalnom modelu ukazuju na to da su na ovaj način ostvarene sve željene karakteristike, te da se ovako realizovan sistem može primeniti na konkretnom rešenju, a to je zamena elektrohidrauličkog servo sistema analognim regulatorom. Time se postojeći sistem zamenjuje savremenim rešenjem i unapređuje jednim novim sistemom sa prelaskom celokupnog upravljanja sa elektrohidrauličkog na električno, bez devastacije karakteristika pogona IC lokatora.

Iz odnosa maksimalnih i minimalnih brzina $80[\mathrm{mrad} / \mathrm{s}] / 0,08[\mathrm{mrad} / \mathrm{s}]$ vidi se da je opseg regulacije brzina 1000. Dobijena ubrzanja su manja nego sa elektrohidrauličkim sistemom (EHSS) pokretanja, što se može objasniti činjenicom da ubrzanje EHSS zavisi od karakteristika hidrauličknog pogona, koji je projektovan za mnogo veću snagu (300 W). Iz namene sistema vidi se da nije neophodno da ima tako velike vrednosti ubrzanja. Pri držanju zadatog položaja dobijene su iste ili bolje karakteristike kao za pogon elektrohidrauličkim servo sistemom.

$\mathrm{Na}$ osnovu izmerenih karakteristika pogona IC lokatora po visini, realizovanog pomoću elektromotora i digitalnog servo regulatora, zaključuje se da je u potpunosti moguće izvršiti supstituciju EHSS ovako realizovanim pogonom, pri čemu su sve zahtevane statičke i dinamičke karakteristike pogona ostvarene na istom ili još boljem nivou nego pri pogonu IC lokatora pomoću EHSS.

Ovakva supstitucija postojećih servo pogona može se izvršiti i na nišanskim spravama, laserskim obeleživačima cilja i drugim sličnim sistemima.

\section{Literatura}

[1] Milić, S., Kontinualni sistemi automatskog upravljanja, Naučna knjiga, Beograd, 1980.

[2] Milić, S., Digitalni sistemi upravljanja, Naučna knjiga, Beograd,1989.

[3] Viličić, A., Daljinski upravljani BGA $30 \mathrm{~mm}$, Report SDPR, Beograd, decembar 2007. 